a few species, notably Aedes aegypti, Culex pipiens, and one or two species of Anopheles, but field workers have studied a large number of vector and suspected vector species in many parts of the world.

Professor J. D. Gillett spent more than twenty years in Africa working both at the bench and in the field on the biology of important vector species. When he started this work the foundations of the subject had been laid and research was developing at advanced levels. His own research encompassed studies of disease transmission, egg diapause, ovarian development and, perhaps most notably, of the role of circadian rhythms in mosquito behaviour. Professor Gillett has now written an account of mosquito biology for the general reader. The reader soon becomes aware of the wide variety of behaviour patterns displayed by a family of structurally similar insects, and of how a knowledge of these behaviour patterns is essential if one is to understand the biology of any species and its interactions with other organisms. The author also emphasizes that mosquito species are composed of partially isolated and largely non-interbreeding populations which can differ greatly in their relationships with man or other vertebrate hosts.

Professor Gillett takes us through the life cycle of mosquitoes, describing the biology of the different stages and often illuminating the text with observations from his own experience. The section on host-seeking is disappointing and some chapters would have been much clearer if they had contained line drawings, but as a whole the book contains an informative and very readable account of the complex and interesting lives of these beautiful and dangerous insects. In the final chapters the author describes the epidemiology of the principal human diseases transmitted by mosquitoes, giving emphasis to yellow fever and to some recently discovered viral diseases. The reader who has some knowledge of biology will gain from this book an understanding of the biology of an important family of insects of which we have remarkably extensive if still incomplete knowledge.

A. N. Clements

\section{Senses of Fish}

Fish Physiology. Edited by W. S. Hoar and D. J. Randall. Vol. 5. Pp. xvi+ 600. (Academic: New York and London, October 1971.) \$32; £14.95.

THIS handsomely produced book is a worthy extension of the multi-volume treatise which aims to cover all aspects of fish physiology in considerable detail As the editors say in the preface: "The chapters in this volume, perhaps more than in other volumes, can only present a summary of the present state of science in this rapidly expanding and developing field." With this statement one would generally agree, though, as in most collaborative efforts of this kind, the contributors display in varying degree the art of abstracting concisely essential points from original research. The number of pages allotted to each topic can, therefore, give only a superficial indication of the state and progress in any one field. The galaxy of experts who contributed is a guarantee of high standards, although some chapters, for example, that on temperature receptors, seem mainly of value in emphasizing the paucity of available information and the need for further work. One can hold different views on the composition, balance and arrangement in this volume. The excellent article on the Mauthner cell might have been better placed in the previous volume in context with the central nervous system. Some apologies are made for inclusion of a very detailed chapter on electric organs, justified by its bearing on electroreception. The derivation of electric organs from neuromuscular elements prompts one to search in vain in present or future volumes for an article dealing with the motor system in fish. This seems a strange omission, for the main bulk of a fish is muscle, which, quite apart from its academic interest, is of great importance to nonspecialist members of the human race. In the end, however, each chapter in this as in the other volumes stands in its own right, only loosely linked to the rest. The scholarly treatment and the inclusion in some chapters of material not previously published are welcome; this contrasts with others which have been reviewed by the same authors with alarming regularity in recent years-in annual reviews, in handbooks of comparative or sensory physiology, in symposia volumes, progress reports and so on. The flood of advertising leaflets arriving daily on one's desk bears witness that the reviewing epidemic shows no signs of abating. This places a prospective buyer of Fish Physiology in a dilemma and provokes some unholy thoughts: he may only want the new bits and is made to pay for the lot. If only some of the advertising money could be deflected into research instead of re-hash! Reviewers of earlier volumes of Fish Physiology have grumbled about the high price ( $£ 88 \mathrm{~s}$ in 1969); the cost of the 1971 volume is 114.95 . The avowed aim of the work is to serve fisheries research laboratories and university reference libraries, and no library which has invested in earlier volumes would wish to break their series. It is fascinating to speculate about the complex web of drives from which springs the publication of such works. It may be the noble wish to minister to the needs of the scientific community; it may be an expression of the business acumen of publishers, combined with the inability of some authors to say "No" when advances are made to them. Certainly a more rational use than we see at present of financial resources available for dissemination of scientific information is conceivable. This is not to say that volume 5 of Fish Physiology is not a useful book to have on one's shelf. It is a landmark in the jungle of proliferating scientific literature.

H. W. LISSMANN

\section{Sugar}

Sugar: Chemical, Biological and Nutritional Aspects of Sucrose. By John Yudkin, Jack Edelman and Leslie Hough. Pp. 246. (Butterworth: London, June 1971.) $£ 4.50$.

IN 1969 the departmental heads of Chemistry, Nutrition and Botany at Queen Elizabeth College, London, combined to organize a symposium on sugar (sucrose). This was long overdue in view of the fact that sucrose is the principal pure chemical in our diet, and it is appropriate that this multidisciplinary symposium should be held at a centre of such high international repute in the field of carbohydrates. This book, which represents the proceedings of the symposium, is the fullest and most up-to-date collection of scientific opinion on the chemistry and biology of sucrose.

The current focus of international opinion on sucrose is due, in large measure, to its effects on mammalian organisms. Many workers allege that the disaccharide may be a contributor to ischaemic heart disease, dental caries, gastrointestinal disorders and many other illnesses. Most of these suggestions, however, are still open to question and indeed doubt, for the replacement of dietary sucrose with other sweeteners may be an even more hazardous undertaking. No medical or physiological advances in our understanding of sugar metabolism can succeed without parallel advances at the molecular level, and although sucrose is structurally well understood the reasons for the biosynthesis of such an asymmetric substance are still obscure. Thus botanically and zoologically the origins and subsequent metabolic fate of the sucrose molecule are under investigation throughout the world.

All scientists, industrialists and medical personnel interested in the uses, effects and future potential of sugar should find this book to be of great value. It is concise and thorough and supported by an excellent bibliography.

G. G. BIRCH 